\title{
Prebiotic effects of inulin and oligofructose
}

\author{
S. Kolida*, K. Tuohy and G. R. Gibson \\ Food Microbial Sciences Unit, School of Food Biosciences, The University of Reading, Whiteknights, Reading, \\ RG6 6AP, UK
}

\begin{abstract}
Prebiotics are non-digestible food ingredients that target certain components within the microbiota of the human large intestine. Efficient prebiotics need to have a specific fermentation therein and thereby have the ability to alter the faecal microflora composition towards a more 'beneficial' community structure. This should occur by the stimulation of benign or potentially health promoting genera but not the harmful groups. Because of their positive attributes bifidobacteria and lactobacilli are the most frequent target organisms. Both inulin and oligofructose have been demonstrated to be effective prebiotics. This has been shown through both in vitro and in vivo assessments in different laboratories. Because of their recognised prebiotic properties, principally the selective stimulation of colonic bifidobacteria, both inulin and oligofructose are increasingly used in new food product developments. Examples include drinks, yoghurts, biscuits and table spreads. Because of the recognised inhibitory effects that bifidobacteria can exert against gut pathogens, one of the most important aspects of prebiotic ingestion is fortification of the gut flora to resist acute infections.
\end{abstract}

\section{Human gut microflora: Prebiotics: Inulin}

\section{Introduction}

Oligosaccharides are major components of various dietary products (e.g. plant cells, milk) and since 1980 their use in functional foods has been increasingly researched (Roberfroid, 2002). Certain non-digestible (in the upper gastrointestinal tract) oligosaccharides are prebiotics. A prebiotic is a non-digestible food ingredient that beneficially affects the host by selectively stimulating the growth and/or activity of one or a limited number of bacteria in the colon, that can improve the host health (Gibson \& Roberfroid, 1995). For a food ingredient to be classified as a prebiotic it must fulfil the following criteria:

- Neither be hydrolyzed, nor absorbed in the upper part of the gastrointestinal tract.

- Be selectively fermented by one or a limited number of potentially beneficial bacteria commensal to the colon, e.g. bifidobacteria and lactobacilli, which are stimulated to grow and/or become metabolically activated.

- Prebiotics must be able to alter the colonic microflora towards a healthier composition, for example by increasing numbers of saccharolytic species while reducing putrefactive microorganisms.

Thus, prebiotic fermentation should be directed towards bacteria seen as health promoting, with indigenous lacto- bacilli and bifidobacteria currently being the preferred targets (Gibson, 1998).

The ultimate aim of supplementation of the human diet with prebiotics is beneficial management of the gut microbiota. The resident bacterial microflora of the human colon comprises approximately $95 \%$ of the total cells of the body and plays a key role in the host nutrition, health and disease. More than 500 different bacterial species have been cultured from human faeces belonging to fifty different genera (Blaut et al. 2002; Tannock, 2002). Of these, there are indications that bifidobacteria are the main health promoting group. Bifidobacteria are thought to play an important role in the improved health and development of breast-fed infants as compared to those which are formula-fed. Bifidobacterium sp. dominate the gut microflora of breast-fed infants. Among the beneficial effects of bifidobacteria are thought to be:

- Protection from enteric infection.

- Lowering of intestinal $\mathrm{pH}$ by formation of acids after assimilation of carbohydrates.

- Suppression of putrefactive and pathogenic bacteria.

- Production of vitamins.

- Activation of intestinal function, assistance of digestion and absorption.

- Stimulation of the immune response.

Abbreviations: GOS, galacto-oligosaccharide; SCFA, short-chain fatty acid; TOS, transgalactosylated oligosaccharide.

Note: For the definition of the terms inulin and oligofructose please refer to the introductory paper (p. S139) and its footnote.

*Corresponding author: Dr S. Kolida, fax +44 (0)1189 357222, email afr99sk@ reading.ac.uk 
Because bifidobacteria are susceptible to oxygen and heat, their application in foods, as probiotics, has been limited in comparison to the lactobacilli. Therefore, there has been much interest in food-grade bifidogenic factors, which endure normal processing and show effectiveness in the human body after ingestion

The prebiotic market is expanding rapidly and the demand for novel compounds may not be limited to oligosaccharides although these are the current market leaders (Crittenden \& Playne, 1996). A variety of products containing inulin and/or oligofructose formulations, claiming to have beneficial effects on gut health and general wellbeing, are starting to become prevalent in the European market. Table 1 gives examples of foodstuffs containing the ingredients, whilst numerous other products existing in supplement form are available in many health food stores.

Inulin and oligofructose are legally classified as food or food ingredients in all countries in which they are used. They are well accepted for food use without limitations (Coussement, 1999).

Inulin and oligofructose are amongst the most studied and well-established prebiotics. Fig. 1 summarises their behaviour and effects in the gastrointestinal tract.

As previously mentioned inulin and oligofrustose escape digestion in the upper gastrointestinal tract and reach the large intestine virtually intact. This attribute constitutes them as being ideal for fermentation in the colon by the saccharolytic resident microbiota. Whilst variable data have ensued on the different application of inulin and oligofructose, it is incontestable that they act as prebiotics. The effects of inulin and oligofructose on the human gut microbiota has been extensively studied both in vivo and in vitro and the majority of the studies report selective fermentation by the beneficial flora, namely bifidobacteria and to lesser extent lactobacilli (Table 2).

Gibson \& Wang (1994) confirmed the prebiotic effects of inulin and oligofructose in an in vitro study. The fermentability was compared to a range of reference carbohydrates in batch culture. Bacterial growth data showed preferential fermentation by bifidobacteria while populations of Escherichia coli and Clostridium perfringens were maintained at relatively low levels. Further pure culture studies confirmed increased ability of bifidobacteria populations to ferment these substrates when compared to glucose. In a later study, Gibson \& Wang (1994) determined the bifidogenic effect of oligofructose in single stage continuous culture systems containing human faecal bacteria. Oligofructose preferentially enriched for bifidobacteria when compared to inulin and sucrose. Experiments with a three-stage continuous culture model of the human colon further confirmed the bifidogenic effect of oligofructose. Karppinen et al. (2000) compared the in vitro fermentability of inulin by human faecal bacteria to that of rye, wheat and oat bran. Inulin was the most rapidly fermented of the test substrates giving most butyrate production and the largest decrease in $\mathrm{pH}$, but also the highest and fastest gas production. Again, the butyrate generating capacity, as well as increased gas formation, does not agree with metabolic profiles exhibited by bifidobacteria.

Kaplan \& Hutkins (2000) screened a selection of twentyeight lactic acid bacteria and bifidobacteria for their ability to ferment inulin and oligofructose on MRS agar. Twelve of sixteen Lactobacillus strains and seven of eight Bifidobacterium strains tested were able to ferment the substrates. Hopkins et al. (1998) also documented the ability of seven Bifidobacterium isolates to utilise a selection of fifteen different carbohydrate sources in $48 \mathrm{~h}$ batch culture experiments. In a continuous culture study Sghir et al. (1998) demonstrated, through molecular techniques, that inulin and oligofructose were selectively fermented not only by bifidobacteria but also by lactobacilli. Oligofructose and galacto-oligosaccharides preferentially supported growth of the test bacteria.

The effect of inulin on faecal bifidobacteria in eight healthy free living humans was investigated by Kruse et al. (1999). Subjects consumed a typical Western diet (45\% energy as fat, $40 \%$ energy as carbohydrate) followed by a reduced fat diet (30\% energy as fat) using inulin as fat replacement (maximum inulin consumed $34 \mathrm{~g}$ per day). Controls consumed identical diets but without inulin supplementation. The effect on faecal flora was monitored using fluorescent probes targeting diagnostic regions of the 16S rRNA molecule. A significant increase in bifidobacterial populations was observed, while short-chain fatty acids (SCFA), blood lipids and gas production remained unaffected. Bouhnik et al. (1999) assessed the tolerance and threshold dose of oligofructose (from sucrose) that significantly increased faecal bifidobacteria counts in a 7-day study of forty healthy human volunteers. They reported that the optimal dose for increased bifidogenesis without significant side effects, such as flatulence, was $10 \mathrm{~g}$ per day. Gibson et al. (1995) studied the selective stimulation of bifidobacteria by inulin and oligofructose in

Table 1. Examples of fructo-oligosaccharide containing foodstuffs in the European market (after Young, 1998)

\begin{tabular}{lll}
\hline Product & \multicolumn{1}{c}{ Company } & \multicolumn{1}{c}{ Active Ingredients } \\
\hline Symbalance (yogurt) & Tonilait (Switzerland) & Three Lactobacillus strains plus inulin \\
Jour apres Jour (milk) & Lactel (France) & Vitamins plus oligofructose (from sucrose) \\
Probiotic plus Oligofructose (yogurt) & Bauer (Germany) & Two Lactobacillus strains plus oligofructose \\
Actiline (spread) & Vamdermoortele (Belgium) & inulin \\
Ligne Bifide dietetic range (biscuits, ready meals) & Vivis (France) & Oligofructose (from sucrose) \\
Aviva (biscuits and chocolate drink) & Novartis (Switzerland) & Oligofructose (from sucrose) \\
Low-sugar sorbet & Thiriet (France) & Oligofructose (from sucrose) \\
Actimel (Cholesterol control yogurt) & Danone (Belgium) & L. acidophilus plus oligofructose (from sucrose) \\
Fysiq (dairy drink) & Mona (Holland) & L. acidophilus plus inulin
\end{tabular}




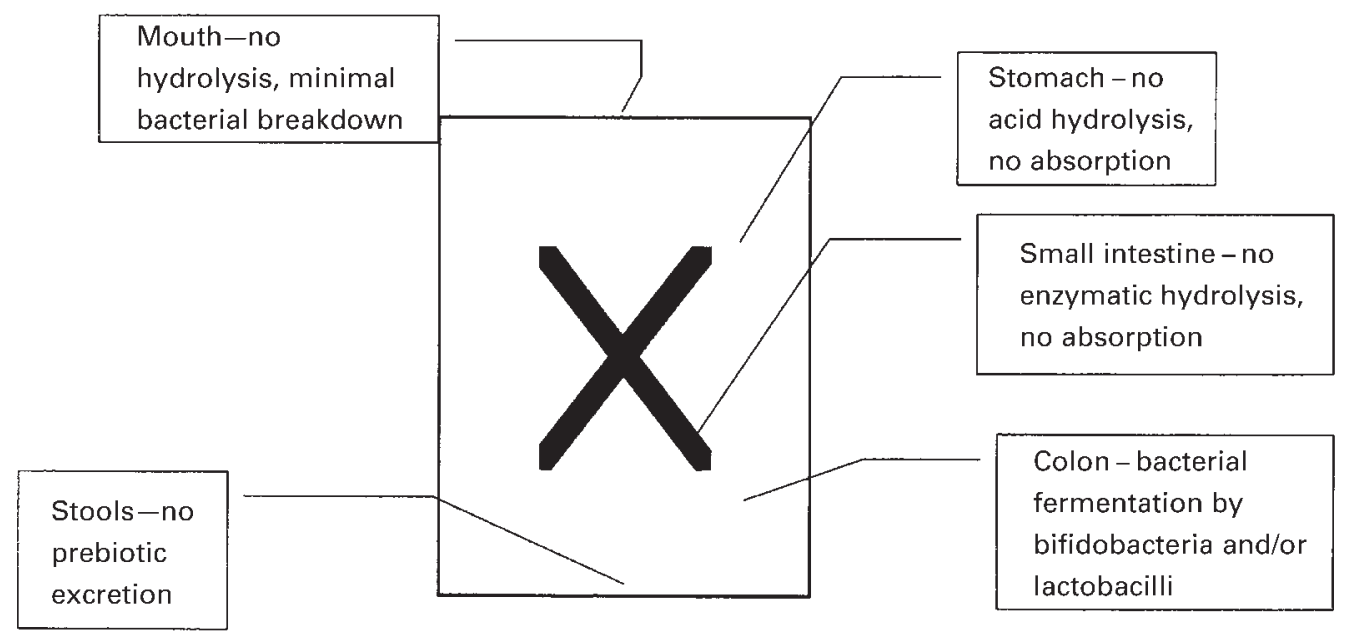

Fig. 1. Behaviour of inulin and oligofructose, as prebiotics, in the human gut.

a 45-day study of eight healthy male human subjects. Volunteers were fed controlled diets of $15 \mathrm{~g} / \mathrm{d}$ sucrose for the first 15 days followed by $15 \mathrm{~g} / \mathrm{d}$ oligofructose for a further 15 days. Four volunteers went on to consume $15 \mathrm{~g} / \mathrm{d}$ inulin for the final 15 days of the study. Both oligofructose and inulin caused significant increases in faecal bifidobacteria. Bacteroides, clostridia and fusobacteria all decreased during oligofructose supplementation and Gram-positive cocci were reduced during inulin supplementation. Total bacterial levels remained unaffected, while little change was observed in faecal SCFA and breath $\mathrm{CH}_{4}$. Wet and dry matter nitrogen and energy excretion was increased with both inulin and oligofructose. Kleessen et al. (1997) studied the effect of dietary supplementation on faecal flora, microbial activity and bowel habit in thirty-five elderly constipated patients. Groups of fifteen and ten patients received lactose and inulin supplements, respectively for 19 days. They were initially administered a $20 \mathrm{~g} / \mathrm{d}$ dose for days $1-8$ which was gradually increased to $40 \mathrm{~g} / \mathrm{d}$ during days $9-11$ and was maintained at these levels until the end of the study. A significant increase was observed in bifidobacterial levels in the inulin group while a decrease in enterococci numbers and enterobacteria occurred. Lactose had no effect on bifidobacteria while it increased enterococci counts and decreased lactobacilli levels. A better laxative effect was reported with inulin. Den Hond et al. (2000) investigated the effect of high performance inulin on constipation in six healthy humans with a low stool frequency in a double-blind placebo control crossover study. Subjects consumed an active diet of $15 \mathrm{~g} / \mathrm{d}$ inulin and a placebo of $15 \mathrm{~g} / \mathrm{d}$ sucrose. A significant increase in stool frequency and faecal bulk was observed with inulin administration. Hunter et al. (1993) carried out a double-blind crossover trial using oligofructose against sucrose, at a dose of $6 \mathrm{~g} / \mathrm{d}$, for the management of irritable bowel syndrome, but no gastrointestinal effects were evident. In a double-blind placebo controlled crossover study of thirty-one healthy human volunteers, the prebiotic effects of biscuits containing a blend of partially hydrolysed guar gum and oligofructose were confirmed using fluorescently labelled molecular probes targeting $16 \mathrm{~S}$ rRNA for the bacteriology. A significant increase in bifidobacterial numbers occurred while bacteroides, lactobacilli, clostridia and total bacteria remained unaffected throughout the study (Tuohy et al. 2001). Bouhnik et al. (1996) studied the effect of a fermented milk product containing Bifidobacterium sp. with or without inulin on faecal bacteriology of twelve healthy human volunteers. The authors observed that addition of the Bifidobacterium fermented milk substantially increased bifidobacterial levels after 12 days, but addition of $18 \mathrm{~g} / \mathrm{d}$ inulin to this formulation did not enhance the effect. Buddington et al. (1996) studied the influence of oligofructose (from sucrose) supplementation on the faecal flora of twelve healthy adult humans. Subjects were fed a controlled diet for 42 days which was supplemented with $4 \mathrm{~g} / \mathrm{d}$ oligofructose (from sucrose) between days 7 and 32. The controlled diet increased bifidobacterial levels but highest increases were observed during oligofructose (from sucrose) supplementation. In a similar study on the effects of $4 \mathrm{~g} / \mathrm{d}$ oligofructose (from sucrose) on ten healthy adult humans, Williams et al. (1994) reported a significant increase in bifidobacteria levels and an increase in lactobacilli in six volunteers. Le Blay et al. (1999) studied the effect of the prolonged intake of oligofructose (from sucrose) in rats. Subjects were fed either a low fibre diet (basal) or the basal diet supplemented with $9 \mathrm{~g} / 100 \mathrm{~g}$ body weight daily for 2,8 or 27-week periods. Supplementation with oligofructose (from sucrose) led to an increase in lactic acid bacteria after 2 weeks without changing total anaerobic bacterial levels. The majority of the effects were however abolished by weeks 8 and 27 of oligofructose (from sucrose) consumption. Djouzi \& Andrieux (1997) performed a trial on germfree rats inoculated with human faecal flora fed either control or active diets with $40 \mathrm{~g} / \mathrm{kg}$ of oligofructose, galacto-oligosaccharide (GOS), or transgalactosylated oligosaccharide (TOS). A significant increase in bifidobacterial levels was observed with oligofructose and TOS as well as increases in $\mathrm{H}_{2}$ and $\mathrm{CH}_{4}$ excretion. In two studies, the effect of inulin on dextran sulphate sodium (DSS) induced colitis rats was reported (Videla et al. 1998; Videla, 1999). It was established that dietary inulin promoted growth of lactobacilli in the rat colon, reduced the severity of DSS induced colitis and reduced the luminal $\mathrm{pH}$ in a wide area extending from left to right colon. 
Table 2. Summary of studies designed to determine the prebiotic effect of fructo-oligosaccharides

\begin{tabular}{|c|c|c|c|}
\hline Oligosaccharide & Mode of study & Evidence of prebiotic effect & Reference \\
\hline Oligofructose, GOS, TOS & In vivo gnotobiotic rats & High increases in bifidobacteria numbers with FOS and TOS & $\begin{array}{l}\text { Djouzi \& } \\
\text { Anrdieux, } 1997\end{array}$ \\
\hline Oligofructose (from sucrose) & In vivo rats & $\begin{array}{l}\text { Increase in lactic acid bacteria after } 2 \text { weeks, but in the long-term any } \\
\text { effect was lost }\end{array}$ & $\begin{array}{l}\text { Le Blay et al. } \\
1999\end{array}$ \\
\hline Inulin & In vivo DSS induced colitis rats & Decrease in luminal pH between left and right colon & Videla, 1999 \\
\hline Inulin & In vivo DSS induced colitis rats & Increase in lactobacilli & $\begin{array}{l}\text { Videla et al. } \\
1998\end{array}$ \\
\hline Inulin & In vivo eight healthy humans & Significant increase in bifidobacteria established by FISH & $\begin{array}{l}\text { Kruse et al. } \\
1999\end{array}$ \\
\hline Oligofructose & In vivo double-blind placebo controlled IBS patients & No therapeutic effect at $6 \mathrm{~g} / \mathrm{d}$ & $\begin{array}{l}\text { Hunter et al. } \\
1993\end{array}$ \\
\hline Oligofructose (from sucrose) & In vivo forty healthy humans & $\begin{array}{l}\text { Significant increase in bifidobacteria levels without excessive gas pro- } \\
\text { duction at } 10 \mathrm{~g} / \mathrm{d}\end{array}$ & $\begin{array}{l}\text { Bouhnik et al. } \\
1999\end{array}$ \\
\hline Inulin and oligofructose & In vivo eight healthy humans & $\begin{array}{l}15 \mathrm{~g} / \mathrm{d} \text { inulin or oligofructose led to bifidobacteria becoming predominant } \\
\text { in faeces }\end{array}$ & $\begin{array}{l}\text { Gibson } \\
\text { et al.1995 }\end{array}$ \\
\hline Inulin and lactose & In vivo twenty-five elderly constipated humans & $\begin{array}{l}\text { Significant increase in bifidobacteria, decreases in enterococci and fuso- } \\
\text { bacteria. Better laxative effect than lactose }\end{array}$ & $\begin{array}{l}\text { Kleessen et al. } \\
1997\end{array}$ \\
\hline Oligofructose & $\begin{array}{l}\text { In vivo double blind placebo controlled crossover study of } \\
\text { thirty healthy humans }\end{array}$ & $\begin{array}{l}\text { Significant increase in bifidobacteria established via FISH at } 7 \mathrm{~g} / \mathrm{d} \text {, no } \\
\text { change in total bacterial levels }\end{array}$ & $\begin{array}{l}\text { Tuohy et al. } \\
2001 \text {, in press }\end{array}$ \\
\hline Oligofructose (from sucrose) & In vivo twelve healthy adult humans & Significant increase in bifidobacteria, no change in total bacteria levels & $\begin{array}{l}\text { Buddington et al. } \\
1996\end{array}$ \\
\hline Oligofructose (from sucrose) & In vivo ten healthy adult humans & Significant increase in bifidobacteria, some increase in lactobacilli & $\begin{array}{l}\text { Williams et al. } \\
1994\end{array}$ \\
\hline BFM and BFM plus inulin & In vivo twelve healthy humans & $\begin{array}{l}\text { Increase in bifidobacteria with BFM but addition of inulin did not } \\
\text { enhance effect }\end{array}$ & $\begin{array}{l}\text { Bouhnik et al. } \\
1996\end{array}$ \\
\hline Inulin & $\begin{array}{l}\text { In vivo six healthy humans (low stool frequency) double } \\
\text { blind placebo controlled crossover study }\end{array}$ & Significant increase in stool frequency and faecal bulk & $\begin{array}{l}\text { Den Hond et al. } \\
2000\end{array}$ \\
\hline Inulin and oligofructose & In vitro human faecal flora batch cultures & $\begin{array}{l}\text { Significant increase in bifidobacteria, suppression of } E \text {. coli and clostri- } \\
\text { dia }\end{array}$ & $\begin{array}{l}\text { Wang \& Gibson, } \\
1993\end{array}$ \\
\hline $\begin{array}{l}\text { Oligofructose and fourteen } \\
\text { other carbohydrates }\end{array}$ & In vitro batch cultures of seven Bifidobacterium isolates & Best supported growth of test bacteria on oligofructose and GOS & $\begin{array}{l}\text { Hopkins et al. } \\
1998\end{array}$ \\
\hline $\begin{array}{l}\text { Inulin, rye, wheat and oat } \\
\text { brans }\end{array}$ & In vitro human fecal batch cultures & $\begin{array}{l}\text { Highest decrease in } \mathrm{pH} \text { with inulin and highest increase in butyrate, } \\
\text { very fast fermentation and high gas production }\end{array}$ & $\begin{array}{l}\text { Karppinen et al. } \\
2000\end{array}$ \\
\hline Oligofructose & $\begin{array}{l}\text { In vitro human faecal flora continuous culture and in vitro 3- } \\
\text { stage gut model }\end{array}$ & Significant bifidogenic effect compared to sucrose and inulin & $\begin{array}{l}\text { Gibson \& Wang, } \\
1994\end{array}$ \\
\hline Oligofructose & Sixteen strains lactobacilli eight bifidobacteria & $\begin{array}{l}\text { Twelve of sixteen lactobacilli and seven of eight bifidobacteria strains } \\
\text { fermented FOS }\end{array}$ & $\begin{array}{l}\text { Kaplan \& Hut- } \\
\text { kins, } 2000\end{array}$ \\
\hline Oligofructose & In vitro human faecal flora continuous culture & $\begin{array}{l}\text { Increases in bifidobacteria. Lactobacilli outcompeted bifidobacteria at } \\
\mathrm{pH} 5 \cdot 2-5 \cdot 4\end{array}$ & Sghir et al. 1998 \\
\hline
\end{tabular}

Abbreviations: GOS (galacto-oligosaccharides), TOS (transgalactosylated oligosaccharides), BFM (Bifidobacterium sp. Fermented Milk), FISH (fluorescent in situ hybridisation).

Unless otherwise stated, observations on the bacterial flora listed in the Table 2 were obtained via microbial culture techniques. 


\section{Conclusion}

The prebiotic effects of inulin and oligofructose have been confirmed in numerous laboratory and human trials. New developments in molecular procedures for diagnostic bacteriology will help determine health applications, and explain mechanisms of effect. A further desirable attribute for prebiotics is the ability to persist towards the distal region of the colon. This is the site of origin of several chronic disease states including colon cancer and ulcerative colitis. It is thought that the microflora in this region of the gut may play an important role in the onset or maintenance of such disorders. Dietary carbohydrate is the main fermentable substrate in the proximal colon and as this is degraded during bacterial fermentation, protein takes over as the dominant fermentable substrate towards distal areas. The products of bacterial protein metabolism include toxic and potentially carcinogenic compounds such as amines, ammonia and phenolic compounds. There is currently much scientific interest in developing prebiotics, which target this region of the colon. This may include FOS of differing molecular sizes, such that the lower degree of polymerisation oligomers are proximally fermented thereby leaving the longer chain prebiotic for more distal colonic activity.

\section{References}

Blaut M, Criggs C, Collins MD, Welling GW, Doré J, Van Loo J $\&$ de Vos W (2002) Molecular biological methods for studying the gut microbiota: the EU human gut flora project. British Journal of Nutrition 87, S203-S211, this issue.

Bouhnik Y, Flourie B, Andrieux C, Bisetti N, Briet F \& Rambaud JC (1996) Effects of Bifidobacterium sp. fermented milk ingested with or without inulin on colonic bacteria and enzymatic activities in healthy humans. European Journal of Clinical Nutrition 50, 269-273.

Bouhnik Y, Vahedi K, Achour L, Attar A, Salfati J, Pochart P, Marteau P, Flourie B, Bornet F \& Rambaud JC (1999) Shortchain fructo-oligosaccharide administration dose dependently increases fecal bifidobacteria in healthy humans. Journal of Nutrition 129, 113-116.

Buddington RK, Williams CH, Chen SC \& Witherly SA (1996) Dietary supplement of neosugar alters the faecal flora and decreases the activities of some reductive enzymes in human subjects. American Journal of Clinical Nutrition 63, 709-716.

Coussement PAA (1999) Inulin and oligofructose: Safe intakes and legal status. Journal of Nutrition 129, S1412-S1417.

Crittenden RG \& Playne MJ (1996) Production, properties and applications of food-grade oligosaccharides. Trends in Food Science and Technology 7, 353-361.

Den Hond E, Geypens B \& Ghoos Y (2000) Effect if high performance chicory inulin on constipation. Nutrition Research 20, 731-736.

Djouzi Z \& Andrieux C (1997) Compared effects of three oligosaccharides on metabolism of intestinal microflora in rats inoculated with a human faecal flora. British Journal of Nutrition 78, 313-324.

Gibson GR (1998) Dietary modulation of the human gut microflora using prebiotics. British Journal of Nutrition 80, S209-S212.

Gibson GR \& Roberfroid MB (1995) Dietary modulation of the human colonic microflora: introducing the concept of prebiotics. Journal of Nutrition 125, 1401-1412.
Gibson GR \& Wang X (1994) Enrichment of bifidobacteria from human gut contents by oligofructose using continuous culture. FEMS Microbiology Letters 118, 121-128.

Gibson GR, Berry Ottaway P \& Rastall RA (2000) Prebiotics: New Developments in Functional Foods. Oxford: Chandos Publishing Limited.

Gibson GR, Beatty ER, Wang X \& Cummings JH (1995) Selective stimulation of bifidobacteria in the human colon by oligofructose and inulin. Gastroenterology 108, 975-982.

Hopkins MJ, Cummings JH \& Macfarlane GT (1998) Interspecies differences in maximum specific growth rates and cell yields of bifidobacteria cultured on oligosaccharides and other simple carbohydrate sources. Journal of Applied Microbiology 85, 381-386.

Hunter JO, Tuffnel Q \& Lee AJ (1993) Controlled trial of oligofructose management of irritable bowel syndrome. Journal of Nutrition 129, 1451-1453.

Kaplan H \& Hutkins RW (2000) Fermentation of fructooligosaccharides by lactic acid bacteria and bifidobacteria. Applied and Environmental Microbiology 66, 2682-2684.

Karppinen S, Liukkonen K, Aura AM, Forsell P \& Poutanen K (2000) In vitro fermentation of polysacharides of rye, wheat and oat brans and inulin by human faecal bacteria. Journal of the Science of Food and Agriculture 80, 1469-1476.

Kleessen B, Sykura B, Zunft HJ \& Blaut M (1997) Effects of inulin and lactose on faecal microflora, microbial activity and bowel habit in elderly constipated persons. American Journal of Clinical Nutrition 65, 1397-1402.

Kruse HP, Kleessen B \& Blaut M (1999) Effects of inulin on faecal bifidobacteria in human subjects. British Journal of Nutrition 82, 375-382.

Le Blay G, Michael C, Blottiere HM \& Cherbut C (1999) Prolonged intake of fructo-oligosaccharides induces a short-term elevation of lactic acid producing bacteria and a persistent increase in cecal butyrate in rats. Journal of Nutrition 129, 2231-2235.

Roberfroid MB (2002) Functional foods: concepts and application to inulin and oligofructose. British Journal of Nutrition 87, S139-S143, this issue.

Sghir A, Chow JM \& Mackie RI (1998) Continuous culture selection of bifidobacteria and lactobacilli from human faecal samples using fructooligosaccharide as selective substrate. Journal of Applied Microbiology 85, 769-777.

Tannock G (2002) Methodologies for quantification of faecal bacteria: application to prebiotic effects. British Journal of Nutrition 87, S199-S201, this issue.

Tuohy KM, Kolida S, Lustenberger A \& Gibson GR (2001) The prebiotic effects of biscuits containing partially hydrolyzed guar gum and fructooligosaccharides - a human volunteer study. British Journal of Nutrition 86, 341-348.

Videla S (1999) Deranged luminal pH homeostasis in experimental colitis can be restored by a prebiotic. Gastroenterology 116, A942.

Videla S, Vilaseca J, Garcia-Lafuente A, Antolin M, Crespo E, Guarner F \& Malagelada JR (1998) Dietary inulin prevents distal colitis induced by dextran sulfate sodium (DSS). Gastroenterology 114, A1110.

Wang X \& Gibson GR (1993) Effects of the in vivo fermentation of oligofructose and inulin by bacteria growing in the human large intestine. Journal of Applied Bacteriology 75, 373-380.

Williams CH, Witherly SA \& Buddington RK (1994) Influence of dietary Neosugar on selected bacteria groups of the human fecal microbiota. Microbial Ecology in Health and Disease 7, 91-97.

Young J (1998) European market developments in prebiotic- and probiotic-containing foodstuffs. British Journal of Nutrition $\mathbf{8 0}$, S231-S233. 